\title{
Grão de milheto em suplementos para terminação de bovinos de corte em sistema integração lavoura e pecuária
}

\author{
Millet grain in supplements for finishing beef cattle in integrated crop and livestock system
}

\author{
ALONSO, Marcell Patachi ${ }^{*}$; MORAES, Eduardo Henrique Bevitori Kling de $^{2}$; PINA, \\ Douglas dos Santos ${ }^{2}$; PEREIRA, Dalton Henrique ${ }^{2}$; HOFFMANN, Alvair ${ }^{3}$; SANSON, \\ Renan Marcelo Medeiros ${ }^{3}$; WRUCK, Flávio Jesus ${ }^{4}$
}

\footnotetext{
${ }^{1}$ Universidade Federal de Mato Grosso, Programa de Pós-Graduação em Ciência Animal, Pontes e Lacerda, Mato Grosso, Brasil.

${ }^{2}$ Universidade Federal de Mato Grosso, Instituto de Ciências Agrárias, Departamento de Zootecnia, Sinop, Mato Grosso, Brasil.

${ }^{3}$ Universidade Federal de Mato Grosso, Sinop, Mato Grosso, Brasil.

${ }^{4}$ Embrapa Arroz e Feijão, Santo Antônio de Goiás, Goiás, Brasil.

*Endereço eletrônico para correspondência: pataki.alonso@yahoo.com.br.
}

\section{RESUMO}

Objetivou-se avaliar o desempenho produtivo e econômico de animais consumindo quatro suplementos diferenciados pelos níveis crescentes de grão de milheto em substituição ao grão de milho, assim como analisar as características nutricionais do pasto de Brachiaria brizantha cv. Marandu em sistema de integração lavoura e pecuária. Foram utilizados 64 novilhos, não castrados, sendo 32 mestiços (Holandês x Nelore) e 32 da raça Nelore, com média de idade de 20 meses e o peso corporal médio inicial de $388 \pm 26 \mathrm{~kg}$. A área experimental constituiu-se de quatro piquetes de 4,68ha, formados com $B$. brizantha cv. Marandu. A massa de forragem total e a massa de forragem potencialmente digestível foram de $5,24 \mathrm{t} /$ ha e $3,39 \mathrm{t} / \mathrm{ha}$, respectivamente. $\mathrm{O}$ experimento foi estruturado segundo um esquema fatorial $(2 \times 4)$ distribuído em delineamento inteiramente casualizado, onde foram avaliados dois grupos genéticos e quatro diferentes níveis de grão de milheto em substituição ao grão de milho na formulação dos suplementos (0\%; 33\%; $66 \%$ e $100 \%)$. A quantidade ofertada de suplemento foi de $4,0 \mathrm{~kg} / \mathrm{animal} / \mathrm{dia}$. Houve efeito de grupo genético sobre o ganho produtivo dos animais, sendo que novilhos Nelore apresentaram melhor desempenho. O ganho de peso médio diário, ganho de peso total e peso corporal final, reduziram linearmente com a substituição do alimento energético grão de milho por grão de milheto nos suplementos. A inclusão de $33 \%$ de grão de milheto em suplementos concentrados promove redução nos dias necessários para a obtenção de animais de peso corporal de $450 \mathrm{~kg}$.

Palavras-chave: desempenho, níveis de inclusão, suplementação, terminação.

\section{SUMMARY}

The objective was to evaluate the performance and economic development of animals receiving four supplements differentiated by the levels of grain of millet as replacement for corn grain, as well as assess nutritional characteristics of pasture of Brachiaria brizantha cv. Marandu in integrated crop and livestock. Used 64 steers, uncastrated, 32 crossbred (Holstein x Nelore) and 32 Nelore, with 20 months average age and $388 \pm 26 \mathrm{~kg}$ initial body weight. The experiment consisted of four paddocks of 4.68 ha, formed by $B$. brizantha cv. Marandu. The availability of dry matter and potentially digestible dry matter was $5.24 \mathrm{t} / \mathrm{ha}$ and $3.39 \mathrm{t} / \mathrm{ha}$, respectively. The work was designed as a factorial arrangement $(2 \times 4)$ in a completely randomized design to evaluate two genetic groups and four different levels of grain instead of millet to maize grain in the formulation of supplements $(0 \% ; 33 \% ; 66 \%$ e $100 \%)$. The quantity supplied of $4.0 \mathrm{~kg} / \mathrm{animal} /$ day. A significant effect of genetic group on productive performance of animals, 
and that Nelore steers have better performance. The average daily weight gain, total weight gain and final body weight decreased linearly with the inclusion of millet in supplements. The replacement of $33 \%$ of the corn grain millet concentrated supplements promotes reduction in the days required to obtain animal body weight of $450 \mathrm{~kg}$.

Keywords: finishing, performance, replacement levels, supplementation.

\section{INTRODUÇÃO}

A dinâmica do crescimento econômico brasileiro traz consigo o aquecimento do mercado estimulado pelo acréscimo no consumo de produtos diversificados, sobretudo, para dietas que contenham proteína de origem animal.

Para o suprimento da demanda de produtos cárneos, é necessário haver eficiência na produção, o que implica à necessidade de aprimorar e adequar às exigências de sanidade, bem-estar animal e meio ambiente (WILKINSON, 2010). Sobretudo a questões ambientais, os sistemas que permitam a conservação de recursos naturais apresentam-se de grande interesse à atualidade frente aos novos conceitos de produção.

A terminação de animais em pastejo em sistemas de integração lavoura e pecuária (ILP) tem se mostrado oportuna para o desenvolvimento de uma bovinocultura sustentável, pois proporciona pastagem para o gado na época da seca e boa cobertura do solo para cultivos posteriores.

Como componente energético em suplementos concentrados, o grão de milheto (Pennisetum americanum) apresenta-se como fonte de grande interesse na alimentação animal. Tal ingrediente possui características nutritivas que o qualificam como possível substituto ao grão de milho na formulação de dietas contendo concentrados.
Diferenças acerca do desempenho (GOES et al., 2005) e da composição do ganho (FREITAS et al., 2006) entre animais da raça Nelore e mestiços apresentam considerável importância na pesquisa conduzida pela comunidade científica nacional. $\mathrm{O}$ conhecimento das informações originadas através de ensaios contrastando distintos grupos genéticos permite a aplicação de tecnologias de produção e o aprimoramento na gestão de sistemas pecuários conferindo a estes melhores desempenhos econômicos.

Objetivou-se com este experimento avaliar dois grupos genéticos, mestiços e Nelore, além de determinar o melhor nível de substituição do alimento energético grão de milho por grão de milheto no suplemento concentrado de bovinos de corte terminados em um sistema de ILP.

\section{MATERIAL E MÉTODOS}

O experimento foi conduzido em uma propriedade particular localizada no município de Santa Carmem no estado de Mato Grosso. A área experimental encontra-se sob as coordenadas geográficas $12^{\circ} 03^{\prime} 52.07^{\prime}$, Sul e 55'21'16.92', Oeste. O desenvolvimento dos trabalhos de campo ocorreu durante o período da seca, entre os meses de junho e setembro do ano de 2010 .

O clima encontrado em Santa Carmem é, de acordo com a classificação de Köppen-Geiger, do tipo Am (clima de monção), ou seja, tropical chuvoso com um pequeno período de chuvas no mês mais seco.

Os dados climáticos referentes às temperaturas durante o período de desenvolvimento do experimento foram registrados da estação automática pertencente ao Instituto Nacional de 
Rev. Bras. Saúde Prod. Anim., Salvador, v.14, n.2, p.350-361 abr./jun., 2013 http://www.rbspa.ufba.br ISSN 15199940

Meteorologia (Tabela 1). Dados referentes à precipitação pluviométrica apresentaram-se nulos durante $\mathrm{o}$ experimento.

A área do sistema de ILP utilizado apresentou, durante cinco anos agrícolas, distintas culturas, sendo iniciado o experimento no ano de 2009/10 (Tabela 2) após o diferimento de pasto por um mês.

Tabela 1. Valores médios diários das temperaturas máximas e mínimas ao longo do período experimental

\begin{tabular}{lcc}
\hline \multirow{2}{*}{ Períodos } & \multicolumn{2}{c}{ Temperaturas Médias $\left({ }^{\circ} \mathrm{C}\right)$} \\
\cline { 2 - 3 } & Máxima & Mínima \\
\hline Jun/Jul (12/06 a 13/07) & 34,52 & 17,52 \\
Jul/Ago (14/07 a 13/08) & 33,68 & 16,19 \\
Ago/Set (14/08 a 13/09) & 36,03 & 17,30 \\
\hline
\end{tabular}

Fonte: Instituto Nacional de Meteorologia.

Tabela 2. Histórico da distribuição das culturas em função do ano agrícola e da época do ano

\begin{tabular}{lcl}
\hline \multirow{2}{*}{ Ano agrícola } & \multicolumn{2}{c}{ Época } \\
\cline { 2 - 3 } & Águas & \multicolumn{1}{c}{ Seca } \\
\hline $2005 / 06$ & Soja $^{1}$ & Sorgo $^{3}+$ B. ruziziensis \\
$2006 / 07$ & Soja $^{1}$ & Milho $^{4}+$ B. ruziziensis \\
$2007 / 08$ & Arroz $^{2}$ & Milheto $^{5}+$ Sorgo $^{3}+$ B. ruziziensis \\
$2008 / 09$ & Soja $^{1}$ & Milho $^{4}+$ B. brizantha cv. Marandu \\
$2009 / 10$ & B. brizantha cv. Marandu $^{2}$ & B. brizantha cv. Marandu \\
\hline
\end{tabular}

${ }^{1}$ Precoce; ${ }^{2}$ Semeado em plantio direto; ${ }^{3}$ Pastejo; ${ }^{4}$ Safrinha; ${ }^{5}$ Semeado sobre o consórcio Sorgo $+B$. ruziziensis que germinaram inadequadamente.

A área destinada à avaliação do pasto de Brachiaria brizantha cv. Marandu e do desempenho produtivo dos animais apresentava a dimensão total de 18,72ha, subdividido em quatro piquetes de 4,68 ha, delimitados internamente por cerca elétrica.

Para avaliação de desempenho produtivo foram utilizados 64 novilhos não castrados, sendo 32 animais da raça Nelore e 32 animais mestiços (Holandês $\mathrm{x}$ Nelore), com média de idade de 20 meses e peso corporal médio inicial de $388 \pm 26 \mathrm{~kg}$. Os animais foram distribuídos aleatoriamente em quatro lotes com pesos semelhantes, sendo cada lote composto de oito animais mestiços e oito animais Nelore. Ao início do experimento, todos os animais foram submetidos ao controle de endo e ectoparasitas.

Foram avaliados oito tratamentos compostos por dois grupos genéticos associados a quatro suplementos alimentares contendo diferentes níveis de substituição do alimento energético grão de milho por grão de milheto (Tabela 3). 
Tabela 3. Distribuição e composição percentual dos suplementos alimentares com base na matéria natural

\begin{tabular}{lcccc}
\hline \multirow{2}{*}{\multicolumn{1}{c}{ Ingredientes }} & \multicolumn{4}{c}{ Níveis de substituição por milheto (\%) } \\
\cline { 2 - 5 } & 0 & 33 & 66 & 100 \\
\hline Mistura mineral $^{1}$ & 2,00 & 2,00 & 2,00 & 2,00 \\
Resíduo de soja moído $_{\text {Grão de milheto moído }}^{55,27}$ & 52,68 & 50,09 & 45,78 \\
Grão de milho moído & - & 14,24 & 28,48 & 52,22 \\
& 42,73 & 31,08 & 19,43 & - \\
\hline
\end{tabular}

${ }^{1}$ Suplemento mineral comercial.

Níveis de garantia: Cálcio 180,0g/kg; Sódio 120,0g/kg; Fósforo 85,0g/kg; Enxofre 15,0g/kg; Magnésio 2,0g/kg; Zinco 4500,0mg/kg; Cobre 1300,0mg/kg; Manganês 1150,0mg/kg; Flúor 830,0mg/kg; Cobalto $85,0 \mathrm{mg} / \mathrm{kg}$; Iodo $85,0 \mathrm{mg} / \mathrm{kg}$; Selênio $24,5 \mathrm{mg} / \mathrm{kg}$.

$\mathrm{O}$ arraçoamento ocorreu próximo às $10 \mathrm{~h}$, sendo a quantidade de suplemento ofertada de $4,0 \mathrm{~kg}$ de matéria natural/animal/dia. Após a pesagem inicial, os tratamentos foram aleatoriamente designados a cada lote, sendo 28 dias o intervalo entre as pesagens subsequentes. Os pesos foram mensurados dos animais sempre no mesmo horário do dia com o objetivo de acompanhar desempenho produtivo dos lotes durante e ao término do experimento. A fim de minimizar algum eventual efeito benéfico inerente a algum piquete, como uma possível variação na massa de matéria seca (MS) de forragem, procedeu-se o rodízio dos grupos de animais a cada 14 dias mantendo-se o fornecimento do respectivo tratamento aos mesmos.

De posse dos dados da massa dos animais determinou-se o ganho de peso total (kg/animal), o ganho de peso médio diário (kg/animal/dia) e os dias necessários para que os animais atingissem a massa de $450 \mathrm{~kg}$ (D450). Para a determinação de ganho de peso total utilizou-se a expressão: GPT = PCF - PCF. Onde: GPT = ganho de peso total $(\mathrm{kg} /$ animal $) ; \mathrm{PCF}=$ peso corporal final $(\mathrm{kg} / \mathrm{animal}) ; \mathrm{PCI}=$ peso corporal inicial (kg/animal). Para o ganho médio diário utilizou-se a expressão: GMD = GPT $/ 84$ dias.
Onde: $\mathrm{GMD}=$ ganho médio diário por animal (kg/animal $/$ dia $) ;$ GPT $=$ ganho de peso total (kg/animal). Para determinação dos dias necessários para que os animais atingissem $450 \mathrm{~kg}$ foi utilizada a seguinte equação: D450 = (PCR - PCI $)$ / GMD. Onde: D450 = número de dias necessários para que o animal atingisse $450 \mathrm{~kg}$; PCR = peso corporal de referência (450 kg/animal); PCI = peso corporal inicial (kg/animal); $\mathrm{GMD}=$ ganho médio diário por animal (kg/animal/dia).

Ao início do experimento e sucessivamente a cada 14 dias, realizouse a coleta de amostras de massa de forragem através do corte de cinco áreas aleatórias de cada piquete experimental. Os cortes foram feitos a uma altura de $0,10 \mathrm{~m}$ do solo, delimitados por um quadrado metálico com dimensão de $0,50 \times 0,50 \mathrm{~m}$. Seguido o corte, as amostras foram pesadas e os valores registrados para posterior determinação da massa de forragem. Em seguida, o material de cada piquete foi homogeneizado, do qual foram coletadas duas subamostras compostas por piquete, sendo, uma para determinação da composição bromatológica e massa total de forragem em $\mathrm{t}$ de $\mathrm{MS} / \mathrm{ha}$ e a outra fracionada para os componentes lâmina foliar verde, lâmina foliar seca, colmo verde e colmo seco, sendo a bainha e a 
inflorescência considerados como colmo.

Das amostras destinadas à estimativa da massa total de forragem foram calculados os percentuais de MS potencialmente digestível (MSPD), sendo o resíduo insolúvel em detergente neutro, obtido após incubação ruminal in situ das amostras por 240 horas (CASALI et al., 2008).

As análises laboratoriais dos alimentos (Tabela 4) foram realizadas de acordo com descrições de Silva \& Queiroz (2002) com exceção das avaliações de FDN que seguiram os métodos descritos por Mertens (2002). A FDN indigestível (FDNi) foi obtida segundo recomendações de Casali et al. (2008) e os teores de nitrogênio insolúvel em detergente neutro (NIDN) e em detergente ácido (NIDA) foram obtidos conforme Licitra et al. (1996).

Os teores de carboidratos totais das amostras foram calculados segundo equação proposta por Sniffen et al. (1992), em que CT $(\%)=100-(\% \mathrm{~PB}+$ $\% \mathrm{EE}+\%$ Cinzas). Para os carboidratos não fibrosos (CNF) da forragem e do suplemento, o cálculo foi realizado por meio da diferença entre CT e FDNcp. Para estimativa de NDT ( $\%$ da MS) da forragem e dos suplementos, utilizou-se o modelo sugerido pelo NRC (2001).

Tabela 4. Média da composição nutricional dos suplementos e do pasto

\begin{tabular}{lrrrrr}
\hline \multirow{2}{*}{ Item } & \multicolumn{3}{c}{ Níveis de substituição por milheto (\%) } & \multirow{2}{*}{ Pasto } \\
\cline { 2 - 5 } & \multicolumn{1}{c}{$0 \%$} & \multicolumn{1}{c}{$33 \%$} & $66 \%$ & $100 \%$ & \\
\hline MS $^{1}$ & 89,63 & 89,76 & 89,89 & 90,12 & 55,85 \\
MSPD $^{2}$ & 83,87 & 85,34 & 85,48 & 84,96 & 64,87 \\
MO $^{3,17}$ & 95,36 & 95,54 & 95,71 & 96,00 & 93,13 \\
MM $^{4,17}$ & 4,64 & 4,46 & 4,29 & 4,00 & 6,87 \\
$\mathrm{~PB}^{5,17}$ & 25,03 & 25,28 & 25,53 & 25,95 & 3,64 \\
$\mathrm{NIDN}^{6,18}$ & 16,53 & 18,55 & 20,57 & 23,94 & 39,72 \\
$\mathrm{NIDA}^{7,18}$ & 6,27 & 6,61 & 6,96 & 7,53 & 17,77 \\
$\mathrm{EE}^{8,17}$ & 12,72 & 12,29 & 11,87 & 11,17 & 1,42 \\
$\mathrm{CT}^{9,17}$ & 57,61 & 57,96 & 58,31 & 58,88 & 88,07 \\
$\mathrm{CNF}^{10,17}$ & 43,68 & 43,73 & 43,78 & 43,85 & 18,12 \\
$\mathrm{FDN}^{11,17}$ & 18,40 & 18,54 & 18,69 & 18,93 & 72,64 \\
$\mathrm{FDNcp}^{12,17}$ & 13,93 & 14,23 & 14,53 & 15,03 & 69,95 \\
$\mathrm{FDNi}^{13,17}$ & 11,42 & 11,70 & 11,98 & 12,44 & 35,49 \\
$\mathrm{FDA}^{14,17}$ & 11,43 & 11,61 & 11,80 & 12,11 & 36,76 \\
LIG $^{15,17}$ & 2,32 & 2,35 & 2,38 & 2,43 & 7,37 \\
$\mathrm{NDT}^{16,19}$ & 88,06 & 87,89 & 87,72 & 87,43 & 48,60 \\
\hline
\end{tabular}

${ }^{1}$ Matéria seca (\%); ${ }^{2}$ Matéria seca potencialmente digestível; ${ }^{3}$ Matéria orgânica; ${ }^{4}$ Matéria mineral;

${ }^{5}$ Proteína bruta; ${ }^{6}$ Nitrogênio insolúvel em detergente neutro; ${ }^{7}$ Nitrogênio insolúvel em detergente ácido;

${ }^{8}$ Extrato etéreo; ${ }^{9}$ Carboidratos totais; ${ }^{10}$ Carboidratos não fibrosos; ${ }^{11}$ Fibra em detergente neutro; ${ }^{12}$ Fibra em detergente neutro corrigida para cinzas e proteína; ${ }^{13}$ Fibra em detergente neutro indigestível; ${ }^{14}$ Fibra em detergente ácido; ${ }^{15}$ Lignina; ${ }^{16}$ Nutrientes digestíveis totais; ${ }^{17} \%$ da MS; ${ }^{18} \%$ do $\mathrm{N}$ total; ${ }^{19}$ Estimado segundo NRC (2001).

O experimento foi delineado segundo esquema fatorial $(2 \times 4)$, sendo dois grupos genéticos e quatro suplementos alimentares, e distribuídos em delineamento inteiramente casualizado (DIC) com duração experimental de 84 dias. $O$ peso corporal inicial foi utilizado como covariável no modelo 
estatístico para as variáveis em estudos e no caso da não significância do mesmo, este parâmetro foi retirado do modelo e a análise foi realizada novamente, sem o mesmo.

Os parâmetros mensurados foram submetidos ao teste de normalidade de Kolmogorov-Smirnov (PROC UNIVARIATE) e avaliados pelo processo de análise de variância (PROC GLM). O comportamento linear $\mathrm{e}$ quadrático para as variáveis respostas foram avaliados por intermédio de contrastes ortogonais (Linear: $-3-113$, Quadrático: 1 -1 -1 1 e Cúbico:-1 3 -3 1), sendo o modelo mais adequado o polinômio de maior grau com $\mathrm{P}<0,05$ (PROC GLM) e os parâmetros do mesmo estimados através do PROC REG. Para todas as análises estatísticas foi utilizado o programa computacional Statistical Analyses System (SAS Institute, 2002), sendo adotado para todos os procedimentos um nível de significância de 0,05 .

O modelo estatístico utilizado para o experimento foi: $Y_{i j k}=\mu+S_{i}+G_{j}+$ $S_{i} * G_{j}+\beta^{*}\left(P I_{i j k}-P I / n\right)+e_{i j k}$. Onde: $Y_{i j k}$ $=$ resposta observada no animal $\mathrm{k}$, do grupo genético $j$, consumindo suplemento $\mathrm{i} ; \mu=$ média geral observada; $S_{i}=$ efeito do suplemento i, i $=(0 \% ; 33 \% ; 66 \% ; 100 \%) ; G_{j}=$ efeito do grupo genético j, j = (Nelore; Mestiço); $S_{i * G_{j}}=$ efeito da interação entre suplemento e grupo genético; $\beta=$ coeficiente de inclinação do modelo linear; $P I_{i j k}=$ covariável peso corporal inicial; $P I / n=$ média geral do peso corporal inicial; $e_{i j k}=$ erro aleatório associado a cada observação.

\section{RESULTADOS E DISCUSSÃO}

As massas médias de forragem total, forragem potencialmente digestível, lâmina foliar verde, lâmina foliar seca, colmo verde e colmo seco de Brachiaria brizantha, cv. Marandu foram de 5,24;3,39;0,74;1,16;1,19 e $2,14 \mathrm{t}$ de $\mathrm{MS} / \mathrm{ha}$, respectivamente (Figura 1).

O valor médio de massa de forragem total obtido neste estudo decorreu em grande parte, pelo diferimento do pasto, assim como pelas características do pasto produzido no sistema de ILP.

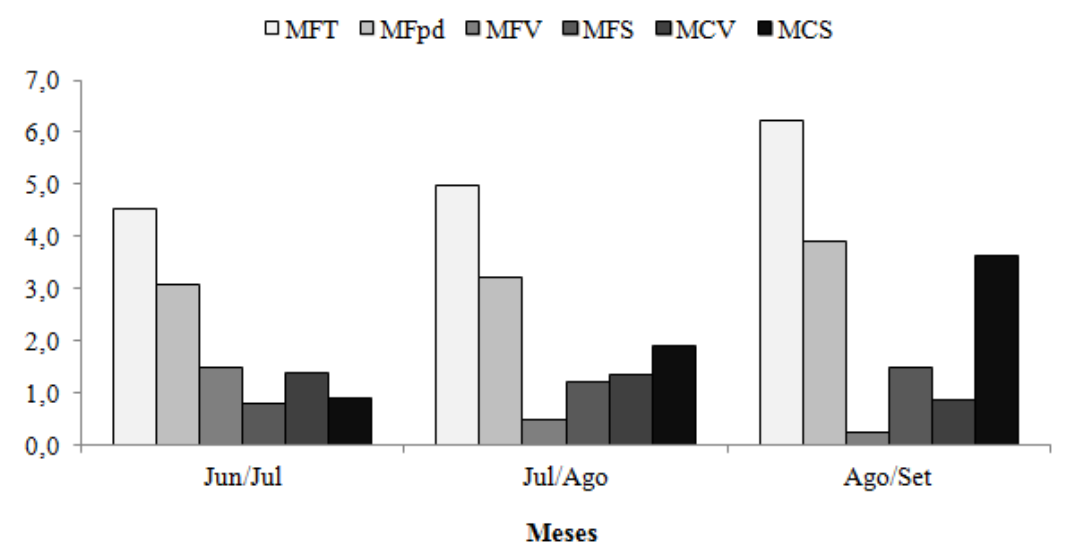

Figura 1. Valores médios de massa de forragem nos períodos experimentais. MFT: massa de forragem total; MFpd: massa de forragem potencialmente digestível; MLV: massa de lâmina foliar verde; MLS: massa de lâmina foliar seca; MCV: massa de colmo verde; e MCS: massa de colmo seco 
Os percentuais de MSPD variaram de um valor mínimo de $61,49 \%$ a um máximo de $68,25 \%$ da massa de forragem total ao longo dos períodos, o que determinou um valor médio de 3,39t de $\mathrm{MFpd} / \mathrm{ha}$, sendo o maior valor correspondente a 3,78t/ha (Ago/Set) e a menor correspondente a 3,01 t/ha (Jun/Jul). Estes resultados podem ser atribuídos aos elevados valores de FDNi (Tabela 4) observados em grande parte da composição do material vegetal morto e em senescência.

Considerações sobre massa, proporções e qualidade nutricional da forragem possuem grande importância devido à influência sobre o consumo de MS de pasto e, consequentemente, sobre o desempenho dos animais em pastejo (SANTOS et al., 2004).

As diferenças observadas pela diminuição na massa de colmo verde e aumento na massa de colmo seco imprimiram um decréscimo na qualidade nutricional da forrageira devido ao aumento nos valores de FDNi do pasto, o que poderia resultar, na diminuição da disponibilidade energética da forragem ao animal.

Os teores de PB da forragem (Tabela 4) apresentaram-se abaixo dos valores descritos por Poppi \& McLennan
(1995) como mínimo para adequada atividade de microrganismos no ambiente ruminal sendo, portanto, um fator que poderia influenciar o consumo de forragem pelo comprometimento da utilização dos substratos energéticos fibrosos potencialmente digestíveis (LAZZARINI et al., 2009), caso a alimentação dos animais fosse exclusivamente a base de forragem, isenta de suplementação concentrada.

Não foi observada significância da interação entre grupo genético e níveis de substituição por milheto $(\mathrm{P}>0,05)$ para o desempenho dos animais (Tabela 5). No entanto, observou-se influência do efeito de grupo genético $(\mathrm{P}<0,05)$, ou seja, animais Nelore apresentaram melhores desempenhos em resposta à suplementação concentrada, possivelmente devido a característica de que animais da raça Nelore suportam melhor o clima tropical. Segundo Poppi \& McLennan (1995), o estresse calórico pode implicar em diminuição da taxa de crescimento para um nível em que o calor possa ser dissipado confortavelmente.

Tal informação permite supor que as condições climáticas (Tabela 2) tenham influenciado negativamente $\mathrm{o}$ desempenho dos animais mestiços.

Tabela 5. Desempenho de bovinos Nelore e mestiços suplementados com níveis crescentes de substituição de grão de milho por grão de milheto

\begin{tabular}{|c|c|c|c|c|c|c|c|c|c|c|c|}
\hline \multirow{2}{*}{ Item } & \multicolumn{2}{|c|}{ GG } & \multirow{2}{*}{ or-P } & \multicolumn{4}{|c|}{ Níveis de grão de milheto (NGM) } & \multirow{2}{*}{$\begin{array}{l}\text { CV } \\
(\%)\end{array}$} & \multirow{2}{*}{ GG $x \mathrm{NGM}^{1}$} & \multicolumn{2}{|c|}{ Contrastes $^{2}$} \\
\hline & Nelo & $\mathrm{M}$ & & $0^{c}$ & $320 /$ & 660 & $100 \%$ & & & $\mathrm{~L}$ & Q \\
\hline 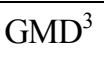 & & & 0 & 0 , & & & & & & & 17 \\
\hline $4 \mathrm{D}$ & 6 & $61,95^{\mathrm{b}}$ & 0,0192 & 68 & 69 & & 50 & 18 & & & 0,1263 \\
\hline $\mathrm{PCF}^{5}$ & $457,65^{\mathrm{a}}$ & $450,09^{\mathrm{b}}$ & 0,0192 & 456,86 & 457,41 & 454,98 & 446,25 & 2,6 & 0,8880 & 0,0131 & 0,1263 \\
\hline
\end{tabular}

${ }^{1}$ GG x NGM = interação entre grupo genético e níveis de substituição de grão de milho por grão de milheto nos suplementos; ${ }^{2}$ Contraste linear $(\mathrm{L})$ e quadrádico $(\mathrm{Q}) ;{ }^{3}$ Ganho de peso médio diário $(\mathrm{kg} / \mathrm{dia})$; ${ }^{4}$ Ganho de peso total $(\mathrm{kg}) ;{ }^{5}$ Peso corporal final $(\mathrm{kg})$. 
Adicionalmente, tem-se o conhecimento de que animais da raça Nelore apresentam melhor aproveitamento de dietas ricas em fibra de baixa qualidade, características do período de seca (Tabela 4). Este baixo valor nutricional do pasto pode ter contribuído para a diferença evidenciada entre os grupos genéticos, sendo os zebuínos Nelore detentores de maior rusticidade (SILVA, 1984; TEODORO, 1996).

De forma similar, Freitas et al. (2011) observaram que bovinos de corte terminados em pastejo apresentaram diferentes respostas ao aporte de nutrientes fornecidos via suplementação em função de diferentes grupos genéticos. Contudo, os autores evidenciaram resposta superior no ganho de peso vivo de animais mestiços em contraste a animais Nelore.

No tocante à inclusão de milheto, verificou-se redução do desempenho produtivo $(\mathrm{P}<0,05)$ para $\mathrm{o}$ variável ganho de peso médio diário (Figura 2), ganho de peso total (Figura 3) e peso corporal final (Figura 4) a partir do aumento dos níveis de substituição do grão de milho por grão de milheto nos suplementos.
Sendo as dietas estudadas neste trabalho balanceadas de forma isoprotéicas, o efeito envolvido no decréscimo de desempenho dos animais apresenta-se sobre a redução na concentração de $\mathrm{N}$ $\mathrm{NH}_{3}$ evidenciada por Ribeiro et al. (2004). Tais autores ao avaliaram os parâmetros ruminais de dietas com inclusão de grão de milheto $(0 ; 25 ; 50$; 75 e $100 \%$ ) e constataram que a medida em que se aumenta os níveis de inclusão do grão de milheto na dieta, este reduz a concentração de $\mathrm{N}_{-} \mathrm{NH}_{3}$ no líquido ruminal.

O efeito provocado, pela redução no $\mathrm{N}^{-\mathrm{NH}_{3}}$ ruminal afeta diretamente o desenvolvimento da população microbiana, particularmente os microrganismos fribrolíticos. $\mathrm{O}$ incremento de $\mathrm{N}-\mathrm{NH}_{3}$ permite, até certo ponto, um aumento na proteína microbiana translocada ao abomaso e posteriormente digerida (HALL \& HUNTINGTON, 2008). Contrariamente, a falta de $\mathrm{N}-\mathrm{NH}_{3}$ reduziria a quantidade de proteína microbiana a ser digerida o que afetaria o desempenho produtivo dos animais.

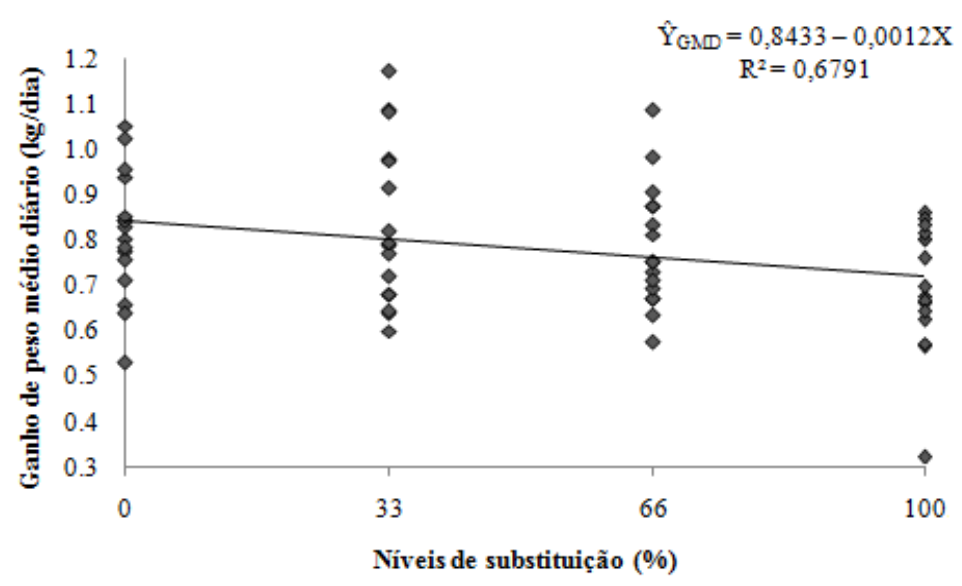

Figura 2. Curva de regressão linear para valores de ganho de peso médio diário $(\mathrm{kg} / \mathrm{dia})$ em função dos níveis crescentes de substituição de grão de milho por grão de milheto $\left[\hat{\mathrm{Y}}_{\mathrm{GMD}}=0,8433( \pm 0,0681)-0,0012\right.$ $\left.( \pm 0,0012) * X ; R^{2}=67,91\right]$ 
Rev. Bras. Saúde Prod. Anim., Salvador, v.14, n.2, p.350-361 abr./jun., 2013 http://www.rbspa.ufba.br ISSN 15199940

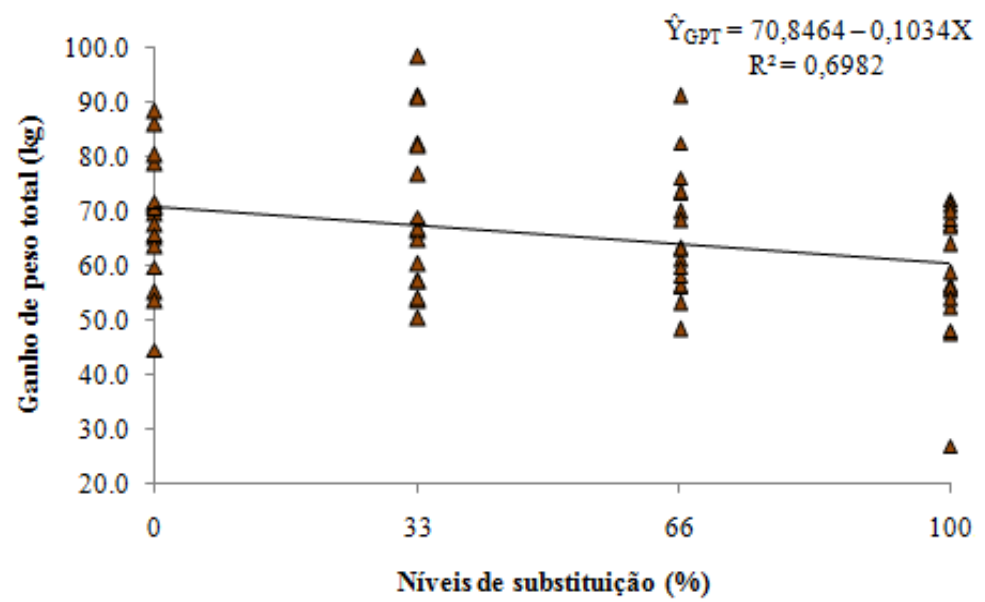

Figura 3. Curva de regressão linear para valores de ganho de peso total $(\mathrm{kg})$ em função dos níveis crescentes de substituição de grão de milho por grão de milheto $\left[\hat{\mathrm{Y}}_{\mathrm{GPT}}=70,8464( \pm 05,4816)-0,1034( \pm 0,0882) * \mathrm{X}\right.$; $\left.\mathrm{R}^{2}=69,82\right]$

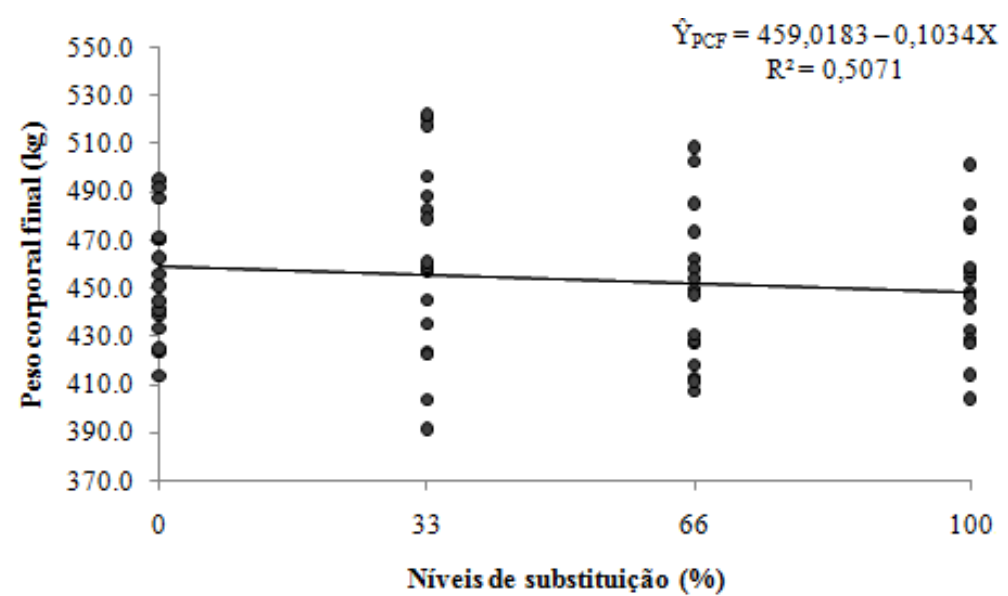

Figura 4. Curva de regressão linear para valores de peso corporal final $(\mathrm{kg})$ em função dos níveis crescentes de substituição de grão de milho por grão de milheto $\left[\hat{\mathrm{Y}}_{\mathrm{PCF}}=459,0183( \pm 05,4816)-0,1034( \pm 0,0882) * \mathrm{X}\right.$; $\left.\mathrm{R}^{2}=50,71\right]$

Adicionalmente, Hill \& Hanna (1990) descreveram que a inclusão de $79 \%$ de grão de milheto na dieta de novilhos de corte promoveu menor digestibilidade aparente tanto da MS quanto da MO, sendo ambas degradabilidades $4,8 \%$ menores do que as degradabilidades da MS e MO para dietas contendo o grão de milho. Assim, é passível que tenha ocorrido o efeito negativo sobre desempenho dos animais em função do menor consumo proporcionado às dietas que incluam níveis elevados de milheto como observado neste trabalho.

Os valores de desempenho observados neste estudo apresentaram-se superiores aos resultados médios descritos por Nascimentoe colaboradores. (2009) em avaliação de diferentes fontes amiláceas (grão de milho e milheto) nos 
suplementos de novilhos em pastejo. Diferentemente deste experimento, os autores não evidenciaram diferenças no desempenho produtivo dos animais alimentados com concentrados contendo milho ou grão de milheto.

Os resultados evidenciados neste estudo contrapõem as descrições de similaridade, ou mesmo, de melhora no desempenho dos animais que consumiam grãos de milheto na dieta.

Segundo a descrição de Gonçalves et al. (2010), bovinos de corte não apresentaram variação para o consumo de MS em dietas de substituição de grãos de milho por grãos de milheto.

Adicionalmente, o comportamento da fermentação do amido de ambos os grãos apresentam-se semelhantes (RIBEIRO et al., 2004), ou ainda, superiores quanto a digestibilidade do amido quando em dietas que apresentem maiores proporções de grão de milheto (GONÇALVES et al., 2010). Hill \& Hanna (1990) sugeriram a utilização do grão de milheto na alimentação de bovinos de corte em recria e terminação, pois poderiam agregar valor nutricional como uma fonte adicional de proteína em dietas que contenham outros grãos com menor percentual de proteína bruta.
Tais proposições, por não influenciarem o consumo e melhorarem o aporte de nutrientes pelo aumento na digestibilidade do amido, influenciariam positivamente no desempenho produtivo dos animais avaliados. Contudo, o efeito do aumento dos níveis de substituição do alimento energético grão de milho por grão de milheto nos suplementos sobre $\mathrm{o}$ desempenho animal, neste experimento, não se apresentaram claros.

Desta forma, ensaios adicionais tornam-se necessários para avaliar o desempenho de bovinos em pastejo alimentados com milheto como principal componente energético da suplementação ou em combinação com outros alimentos.

Segundo Porto et al. (2009), um fator a ser considerado na aplicação da técnica de suplementação concentrada é o ganho proporcionado pela desocupação da pastagem que promove a liberação da área recém utilizada para categorias de animais mais jovens e mais eficientes na conversão de alimentos.

Segundo os resultados descritos na Tabela 6, a desocupação dos animais que receberam suplementos com 33\% de inclusão de grão de milheto ocorreu mais cedo, apresentando, quando comparados aos tratamentos $66 \%$ e $100 \%$, uma diferença de tempo em 15 dias.

Tabela 6. Valores de ganho de peso médio diário, ganho de peso total e dias necessários para que os animais atingissem o peso corporal de $450 \mathrm{~kg}$ (D450)

\begin{tabular}{lcccc}
\hline \multirow{2}{*}{ Variáveis } & \multicolumn{4}{c}{ Níveis de grão de milheto (\%) } \\
\cline { 2 - 5 } & $0 \%$ & $33 \%$ & $66 \%$ & $100 \%$ \\
\hline Ganho de peso médio diário (kg/animal/dia) & 0,816 & 0,826 & 0,797 & 0,691 \\
Ganho de peso total (kg/animal) & 68,54 & 69,38 & 66,94 & 58,04 \\
D450 & 78 & 70 & 85 & 85 \\
\hline
\end{tabular}

As respostas evidenciadas em D450 encontram-se em função do ganho de peso médio diário dos animais. À medida que se aumenta o desempenho produtivo diário dos animais tem-se uma relação inversa com a D450, ou 
seja, quanto maior for o ganho médio diário, menor será o tempo de ocupação dos animais no pasto abreviando a fase de terminação, o que na prática permite a liberação da área para novos animais.

Salienta-se que a atividade desenvolvida em um sistema de integração lavoura e pecuária possibilita vislumbrar maiores retornos econômicos pela otimização de recursos alimentares gerados (resíduos da lavoura), passíveis de utilização na produção de suplementos.

Novilhos Nelores terminados em sistema de integração lavoura e pecuária, no período de seca, apresentam melhores desempenhos produtivos em relação a novilhos mestiços (Holandês x Nelore). A inclusão de $33 \%$ de milheto como componente energético em suplementos concentrados promove melhor desempenho produtivo dos animais independentemente do grupo genético.

\section{REFERÊNCIAS}

CASALI, A.O.; DETMANN, E.; VALADARES FILHO, S.C.; PEREIRA, J.C.; HENRIQUES, L.T.; FREITAS, S.G.; PAULINO, M.F. Influência do tempo de incubação e do tamanho de partículas sobre os teores de compostos indigestíveis em alimentos e fezes bovinas obtidos por procedimentos in situ. Revista Brasileira de Zootecnia, v.37, n.2, p.335-342, 2008.

FREITAS, D.; FREGADOLLI, F.L.; BERTIPAGLIA, L.M.A.; MELO, G.M.P.; REIS, R.A.; BERCHIELLI, T.T. Suplementação da dieta de novilhos de três grupos genéticos em pastagem de Brachiaria brizantha cv. Marandu. Acta Scientiarum. Animal Sciences, v.33, n.4, p.417-425, 2011.
FREITAS, J.A.; QUEIROZ, A.C.; DUTRA, A.R.; VIEIRA, R.A.M.; LANA, R.P.; LEONEL, F.P.; HENRIQUE, D.S.; LIMA, A.V.; SOUZA, J.C. Composição do ganho e exigências de energia e proteína para ganho de peso em bovinos Nelore puros e mestiços. Revista Brasileira de

Zootecnia, v.35, n.3, p.886-893, 2006.

GOES, R.H.T.B.; MANCIO, A.B.; LANA, R.P.; ALVES, D.D.; LEÃO, M.I.; SILVA, A.T.S. Recria de novilhos mestiços em pastagens de Brachiaria brizantha, com diferentes níveis de suplementação, na região Amazônica. Desempenho animal. Revista Brasileira de Zootecnia, v.34, n.5, p.1740-1750, 2005.

GONÇALVES, J.R.S.; PIRES, A.V.; SUSIN, I.; LIMA, L.G.; MENDES, C.Q.; FERREIRA, E.M. Substituição do grão de milho pelo grão de milheto em dietas contendo silagem de milho ou silagem de capim-elefante na alimentação de bovinos de corte. Revista Brasileira de

Zootecnia, v.39, n.9, p.2031-2039, 2010.

HALL, M.B.; HUNTINGTON, G.B. Nutrient synchrony: sound in theory, elusive in practice. Journal of Animal Science, v.86, p.E287-E292, 2008.

HILL, G.M.; HANNA, W.W. Nutritive characteristics of pearl millet grain in beef cattle diets. Journal of Animal Science, v.68, p.2061-2066, 1990.

LAZZARINI, I.; DETMANN, E.; SAMPAIO, C.B.; PAULINO, M.F.; VALADARES FILHO, S.C.; SOUZA, M.A.; OLIVEIRA, F.A. Dinâmicas de trânsito e degradação da fibra em detergente neutro em bovinos alimentados com forragem tropical de baixa qualidade e compostos nitrogenados. Arquivo Brasileiro de Medicina Veterinária e Zootecnia, v.61, p.635-647, 2009. 
LICITRA, G.; HERNANDES, T.M.; Van SOEST, P.J. Standardization of procedures for nitrogen fractionation of ruminants feeds. Animal Feed Science and Technology, v.57, p.347-358, 1996.

MERTENS, D.R. Gravimetric determination of amylase-treated neutral detergent fibre in feeds with refluxing beakers or crucibles: collaborative study. Journal of AOAC International, v.85, p.1217-1240, 2002.

NASCIMENTO, M.L.; PAULINO, M.F.; DETMANN, E.; VALADARES FILHO, S.C.; PORTO, M.O.; SALES, M.F.L. Fontes de energia em suplementos múltiplos para recria de novilhos mestiços em pastejo durante o período de transição seca/águas: desempenho produtivo e características nutricionais. Revista Brasileira de Zootecnia, v.38, n.6, p.1121-1132, 2009.

NATIONAL RESEARCH COUNCIL NRC. Nutrient Requeriments of Dairy Cattle. 7.ed. Washington, D.C.: National Academy of Science, 2001. 363p.

PORTO, M.O.; PAULINO, M.F.; VALADARES FILHO, S.C.; SALES, M.F.L.; LEÃO, M.I.; COUTO, V.R.M. Fontes suplementares de proteína para novilhos mestiços em recria em pastagens de capim-braquiária no período das águas: desempenho produtivo e econômico. Revista Brasileira de Zootecnia, v.38, n.8, p.1553-1560, 2009.

POPPI, D.P.; McLENNAN, S.R. Protein and energy utilization by ruminants at pasture. Journal of Animal Science, v.73, p.278-290, 1995.

RIBEIRO, C.V.D.M.; PIRES, A.V.; SIMAS, J.M.C.; SANTOS, F.A.P.; SUSIN, I.; OLIVEIRA JUNIOR, R.C. Substituição do grão de milho pelo milheto (Pennisetum americanum) na dieta de vacas holandesas em lactação.

Revista Brasileira de Zootecnia, v.33, n.5, p.1351-1359, 2004.

SANTOS, E.D.G.; PAULINO, M.F.; QUEIROZ, D.S.; VALADARES FILHO, S.C.; FONSECA, D.M.; LANA, R.P. Avaliação de pastagem diferida de Brachiaria decumbens Stapf. 1. Características químico-bromatológicas da forragem durante a seca. Revista Brasileira de Zootecnia, v.33, n.1, p.203-213, 2004.

SAS Institute. Statistical analysis system: user's guide: statistics. Version 9.1. 4.ed. Cary. NC., 2002.

SILVA, J.F.C. O ruminante e o aproveitamento de subprodutos fibrosos. Informe Agropecuário, v.10, n.119, p.815, 1984.

SILVA, D.J.; QUEIROZ, A.C. Análise de alimentos: métodos químicos e biológicos. 3ed. Viçosa, MG: Universidade Federal de Viçosa, 2002. $235 \mathrm{p}$.

SNIFFEN, C.J.; O'CONNOR, J.D.; VAN SOEST, P.J.; FOX, D.G.; RUSSEL, J.B. A net carbohydrate and protein system for evaluating cattle diets: II. Carbohydrate and protein availability. Journal of Animal Science, v.70, p.3562-3577, 1992.

TEODORO, R.L. Pesquisa em cruzamentos: resultados zootécnicos. Cadernos Técnicos da Escola de Veterinária da UFMG, n.18, p.11-18, 1996.

WILKINSON, J. Transformações e perspectivas dos agronegócios brasileiros. Revista Brasileira de Zootecnia, v.93, p.26-34, 2010. Supl.

Data de recebimento: $24 / 10 / 2012$

Data de aprovação: 09/06/2013 